\title{
Management of Plant Pathogens using Silver Nanoparticles (AgNPs)
}

\author{
R. Surega ${ }^{1}$, B. Anita ${ }^{2}$ and S. Ramakrishnan ${ }^{2}$ \\ ${ }^{1}$ MTCA, Pudukkottai, India \\ ${ }^{2}$ TNAU, Coimbatore, India
}

*Corresponding author

A B S T R A C T

\begin{tabular}{|c|}
\hline Keywords \\
\hline $\begin{array}{l}\text { Agri } \\
\text { nanotechnology, } \\
\text { Silver } \\
\text { nanoparticles, } \\
\text { Nematology, Plant } \\
\text { pathogens }\end{array}$ \\
\hline Article Info \\
\hline $\begin{array}{l}\text { Accepted: } \\
\text { 15 January } 2020 \\
\text { Available Online: } \\
10 \text { February } 2020\end{array}$ \\
\hline
\end{tabular}

Keywords

Agri

Silver

Nematology, Plant

pathogens

Article Info

Accepted

Available Online:

February 2020

\section{Introduction}

Changes in agricultural technology have been a major factor shaping modern agriculture. Consequently, innovative technologies are being introduced in modern agriculture to minimize losses caused by the above biotic stress. Among such technological innovations, nanotechnology is gathering noteworthy considerations due to its robust applications in many fields including agriculture because of its unique physical, chemical and biological properties (Nair et al., 2010; Ghormade et al., 2011 and Bakshi et al., 2014) Nowadays, the exploitation of potentiality of metal nanoparticles is still largely unexplored for crop protection and presently there has been a growing interest to utilize their antimicrobial property for the management of plant disease causing organisms and phytonematodes.

Although nanotechnology has wider application in agriculture very meagre work has been carried out in plant protection. The work carried out so for the management of 
pest and disease problem indicated the possession of antifungal and antibacterial properties by nanoparticles (Carmen et al., 2003). However, almost no information is available about their antinemic properties.In this context Joseph and Morrison (2006) opined that in the near future nanostructured catalysts play an important role to increase the efficacy of commercially available pesticides and reduce their level of dosage required to combat pest problem in agricultural and horticultural crops.

\section{Plant pathogens}

Considerable work has been carried out on the effect of nanoparticles against disease causing plant pathogens like fungi and bacteria compared to insects and phytonematodes. The information available in the literature on the effects of NPs is summarized below.

\section{Fungal plant pathogens}

In an experiment $\mathrm{ZnO}$ and $\mathrm{MgO}$ NPs were evaluated against Alternaria alternate, Fusarium oxysporum, Rhizopus stolonifer and Mucor plumbeus at different concentrations. The study revealed that higher concentrations of NPs were most effective than lower concentrations to inhibit the germination of spores of above fungi (Wani and Shah, 2012). Similarly Wani and Shah (2012) also reported that higher concentrations of NPs with magnesium iron and zinc in vitro inhibited spores germination of Penicillium notatum, Aspergillus niger and Nigrospora oryzae. The same trend was also confirmed by Yehia et al., (2013) with ZnO NPs against two pathogenic fungi viz., Fusarium oxysporum and P. expansum.

\section{Post-harvest pathogens}

He et al., (2011) reported that ZnO NPs @ 3 $\mathrm{mmol} / \mathrm{L}$ significantly inhibited the growth of two postharvest pathogenic fungi viz., Botrytis cinerea and $P$. expansum compared to $B$. cinerea. In this study the pathogen $P$. expansum was found to be more sensitive to the treatment with $\mathrm{ZnO}$ NPs. Further the authors reported that the $\mathrm{ZnO}$ NPs inhibited the growth of $B$. cinerea by causing deformation of fungal hyphae and by affecting their cellular functions.

In addition the $\mathrm{ZnO}$ NPs were also found to prevent the development of conidiophores and conidia of $P$. expansum which eventually led to the death of fungal hyphae. Chowdappa et al., (2014) synthesized AgNPs using chitosan as reducing and stabilizing agent and evaluated against Colletotrichum gloeosporioides in mango (cv. Alphonso). In this study the authors proved that postharvest decay in mango can be minimized by chitosan mediated AgNPs and concluded that the technology has commercial value.

\section{Antimicrobial properties of NPs with special reference to AgNPs}

Antinemic in free living nematode and plant parasitic nematodes

The free living nematode is the most frequently studied nematode for the influence of AgNPs (Yeon Roh et al., 2009; Lim et al., 2012; Meyer et al., 2010 and Yang et al., 2012). The results of the study indicated that the AgNPs affecting behavior and development of the nematodes was toxic to $C$. elegans.

\section{Meloidogyne incognita}

In an experiment conducted in vitro and under controlled pot conditions for the effect of AgNPs, $\mathrm{SiO}_{2}$ and $\mathrm{TiO}_{2}$ against $M$. incognita. It is observed that there was cent percent immobility and mortality of $\mathbf{J}_{2}$ of root knot nematode by the above NPs with 800,400 
and $200 \mathrm{mg} \mathrm{ml} / \mathrm{lit}$ except $\mathrm{SiO}_{2}$. However under pot experimentations $\mathrm{AgNPs}$ and $\mathrm{TiO}_{2}$ were found to reduce the shoot height and root length of tomato compared to untreated control. Hence the authors opined that NPs are causing toxic effect on tomato (Ardakani, 2013). Cromwell et al., (2014) observed that more than 99 per cent of $\mathbf{J}_{2}$ of $M$. incognita became inactive on exposure to AgNPs in water at 30 to $150 \mu \mathrm{g} / \mathrm{ml}$ under laboratory conditions.

\section{M. graminis}

In turfgrass AgNPs reduced $M$. graminis population in soil by 92 and 82 per cent after 4 and 2 days of exposure under field conditions. Similarly the biweekly application of $90.4 \mathrm{mg} / \mathrm{m}^{2}$ of AgNPs caused reduction in gall formation in root and improved quality of turfgrass for two years without phytotoxicity (Cromwell et al., 2014).

\section{Antifungal properties of AgNPs under in vitro conditions}

Gajbhiye et al., (2009) evaluated the effect of AgNPs along with fluconazole for the antifungal activity against Phoma glomerata, $P$. herbarum, $F$. semitectum, Trichoderma sp. and Candida albicans. In this study the authors observed that the antifungal activity of fluconazole enhanced against the test fungi in the presence of AgNPs. The fluconazole in combination with AgNPs showed the maximum inhibitory effect against $C$. albicans followed by $P$. glomerata and Trichoderma sp. whereas no significant enhancement in the inhibitory effect was noticed against P.herbarum and $F$. semitectum.

Various forms of silver ions and nanoparticles were tested for their antifungal activity against plant pathogenic fungi viz., Bipolaris sorokiniana and Magnaporthe grisea. The study conducted by Jo and Kim (2009) indicated that both forms inhibited colony formation of above pathogens. In this assay the effective concentrations (EC50) of the silver compounds to inhibit the colony formation was found to be higher for $B$. sorokiniana than for $M$. grisea.

The fungal hyphal growth of sclerotium forming species viz., Rhizoctonia solani, Sclerotinia sclerotiorum and $S$. minor inhibited remarkably by AgNPs in a dose dependent manner. The antimicrobial property of the AgNPs was differing among the fungi and it was in the order of $R$. solani > S. sclerotiorum > S. minor (Min et al., 2009).

A study on fungal sclerotial germination revealed that the nanoparticles had significant inhibitory effect. Further it is stated that the sclerotial germination of S. sclerotiorum was most effectively inhibited at lower concentrations of AgNPs. In addition it is observed that the hyphae of $S$. sclerotiorum damaged severely by the AgNPs and resulting in the separation of layers of hyphal wall and collapsing of hyphae.

Hence the authors suggested the possibility of using AgNPs as an alternative to pesticides for the management of scleotium forming phytopathogenic fungi. Kim et al., (2012) treated silver colloidal solution at the concentrations of $10,25,50$, and $100 \mathrm{ppm}$ against eighteen different plants pathogenic fungi on potato dextrose agar, malt extract agar and corn meal agar plates.

The results indicated that AgNPs possess antifungal properties against these plant pathogens at $100 \mathrm{ppm}$. Green synthesized AgNPs using Acalypha indica leaf extracts were tested on fungal plant pathogens viz., Alternaria alternata, S. sclerotiorum, Macrophomina phaseolina, Rhizoctonia solani, Botrytis cinerea and Curvularia 
lunata. The results showed that $15 \mathrm{mg}$ concentration of AgNPs showed excellent inhibitory activity against all the tested pathogens (Krishnaraj et al., 2012). Sahayaraj et al., (2012) reported that plant based AgNPs inhibited the growth of Fusarium oxysporum f.sp. vasinfectum affecting cotton.

Elumalai and Vinothkumar (2013) demonstrated the effectiveness of biogenic synthesized AgNPs using aqueous extract of shade dried leaves of Conyza ambigua against Aspergillus niger, A. flavus and S. rolfsii. Banadkouki et al., (2013) found that AgNPs was effective for the management of $F$. solani causing dry rot of potato under storage conditions and also suggested the opt time of application of AgNPs for the management of the fungus.

Bholay et al., (2013) documented that there is a synergistic effect when fluconazole combined with AgNPs in the management of A. alternate, $F$. oxysporum and Cladosporium herbarum. Pulit et al., (2013) proved that nanosilver at $50 \mathrm{ppm}$ inhibited the growth of C. cladosporoides and A. niger by 90 and 70 per cent respectively. Narayanan and Park (2014) evaluated the green synthesized NPs against wood degrading fungal pathogens viz., Gloeophyllum abietinum, G. trabeum, Chaetomium globosum and Phanerochaete sordida and proved its effectiveness.

Papaiah et al., (2014) considered that metallic AgNPs as an alternative to synthetic chemicals for the management of stem rot causing $S$. rolfsii, dry root rot causing $R$. bataticola and collar rot causing $A$. niger. Ouda (2014) reported that AgNPs and CuNPs were effective against $A$. alternata and $B$. cinerea.

In this study it is observed that $15 \mathrm{mg} / \mathrm{lit}$ exhibited maximum inhibitory effect on the growth of fungal hyphae through damaging its hyphae and conidia.

\section{Combined effect of AgNPs with other} metal NPs

Almost no work has been carried out on the combined effect of AgNPs with other metal NPs against plant pathogenic fungi. However Ouda (2014) observed higher effectiveness of AgNPs against $A$. alternata and $B$. cinerea when compared to AgNPs in combination of CuNPs. The AgNPs at 100 ppm caused maximum inhibitory effect on the growth of fungal hyphae as well as conidial germination of anthracnose Colletotrichum sp. in pepper and fungal pathogens responsible for causing powdery mildew on cucumber and pumpkin (Lamsal et al., 2011).

\section{Under greenhouse conditions}

Nanosilver at $7 \mathrm{ppm}$ exhibited inhibitory effect on $S$. cepivorum by more than 90 per cent and increased biomass and dry weight of onion (Jung et al., 2010). The spraying of AgNPs on rice seedlings was highly effective against $M$. grisea according to Elamawi et al., (2013). In this study the SEM image revealed the AgNPs caused detrimental effect on the growth of fungal mycelia. Sandhya et al., (2014) noticed complete inhibition of conidial germination of B. sorokiniana causing spot blotch disease of wheat by AgNPs.

In this experiment the histochemical studies revealed deposition of lignin in vascular bundles due to AgNPs. The nanosized silica silver consisting of nanosilver and silica molecules at $3 \mathrm{ppm}$ exhibited antifungal activity against many phytopathogenic fungi viz., B. cinerea, R. solani, C. gloeosporioides, $M$. grisea and Pythium ultimum. In contrast, a number of beneficial bacteria or plant pathogenic bacteria viz., Escherichia coli, Bacillus subtilis, Pseudomonas syringae pv. syringae, Xanthomonas campestris pv. vesicatoria, Azotobacter chrococuum and 
Rhizobium tropici were found to be affected at higher concentration of $100 \mathrm{ppm}$ of nanosized silica silver (Park et al., 2006). However the authors concluded that the effectiveness of nanosized silica silver was higher in respect of pathogen causing powdery mildews of pumpkin.

\section{In plant growth chamber}

Both ionic and AgNPs significantly checked the fungal pathogens viz., B. sorokiniana and $M$. grisea on perennial ryegrass. In plant growth chambers both silver ions and AgNPs influenced spore colonization and progression of disease. The study concluded that the efficacy of silver ions and AgNPs was greater. Therefore, it can be used as preventive measure since it promotes the direct contact with spores and germ tubes and affect their viability (Jo and Kim, 2009).

\section{In vivo conditions}

It is observed that AgNPs inhibited Colletotrichum sp. in a field experiment conducted by Lamsal et al., (2011). On observations through SEM it is understood that AgNPs causing detrimental effect on mycelial growth of the fungus. Park et al., (2006) evaluated nanosized silica silver (0.3 ppm) against pathogen causing powdery mildew of pumpkin and found to be effective under field conditions.

\section{Antibacterial properties of nanoparticles under in vitro conditions}

The green synthesized AgNPs with Ulva fasciata inhibited the growth of $X$. campestris pv. malvacearum with zone of inhibition of $14.00 \pm 0.58 \mathrm{~mm}$. In this study the minimum inhibitory concentration was fixed as $40.00 \pm 5.77 \mu \mathrm{g} / \mathrm{mL}$ (Rajesh et al., 2012). Similarly another plant based AgNPs was reported to inhibit the growth of same bacterium with $10.33 \pm 0.33 \mathrm{~mm}$ zone of inhibition by Sahayaraj et al., (2012). The green synthesized AgNPs using leaf and fruit extracts of oak (Quercus infectoria) showed antibacterial activity against the plant pathogenic bacteria viz., Pectobacterium carotovorum, Ralstonia solanacearum, Erwinia amylovora and X. citri (Mahmood Chahardooli et al., 2014).

\section{Under glasshouse conditions}

The DNA-directed AgNPs developed by Ismail Ocsoy et al., (2013) eff ectively decreased the disease incidence of bacterial spot caused by $X$. perforans in tomato. In this study even low concentration of $16 \mathrm{ppm}$ of AgNPs had significant advantages of improved stability and stronger adsorption properties with excellent antibacterial effect.

\section{References}

Ardakani, A.S. 2013. Toxicity of silver, titanium and silicon nanoparticles on the root knot nematode, Meloidogyne incognita and growth parameters of tomato. Nematology, 15: 671-677.

Bakshi, M., H.B. Singh and P.C. Abhilash. 2014. The unseen impact of nanoparticles: More or less. Curr. Sci., 106: 350-352.

Banadkouki, H.Z., R.T. Afshari, J. Shaterian and H. Michael. 2013. Do nano silver treatments control dry rot agent inoculated young and aged potato seed tubers?. International Journal of Agronomy and Plant Production, 4(12): 3301-3307.

Bholay, A.D., P.M. Nalawade and B.V. Borkhataria. 2013. Fungicidal potential of biosynthesized silver nanoparticles against phytopathogens and potentiation of fluconazole. World Research Journal of Pharmaceutical Research, 1(1): 12-15.

Carmen, I.M., P. P. Chithra, Q. Huang, T. Paul, S. Liu and L. Kokini Jozef. 2003. Nanotechnology: A new frontier in food Science. Food Technology, 57: 24-29.

Chowdappa, P., C. Shivakumar Gowda, S. Chethana and S. Madhura. 2014. 
Antifungal activity of chitosan silver nanoparticle composite against Colletotrichum gloeosporioides associated with mango anthracnose. African Journal of Microbiology Research, 8(17): 1803-1812.

Cromwell, W.A., J. Yang, J.L. Starr and Young Ki Jo. 2014. Nematicidal effects of silver nanoparticles on root knot nematode in bermuda grass. Journal of Nematology, 46(3): 261-266.

Elamawi, B.C, M.A. Rabab and R.A.S. El-Shafey. 2013. Inhibition effects of silver nanoparticles against rice blast disease caused by Magnaporthe grisea. Egypt. J. Agric. Res., 91 (4): 1271-1283.

Elumalai, E.K and P. Vinothkumar. 2013. Role of silver nanoparticle against plant pathogens. Nano Biomed. Eng., 5(2): 90-93.

Ghormade, V., M.V. Deshpande and K.M. Paknikar. 2011. Perspectives for nano biotechnology enabled protection and nutrition of plants. Biotechnol. Adv., 29: 792-803.

He, Y., Z. Du, H. Lv, Q. Jia, Z. Tang, X. Zheng, K. Zhang and F. Zhao. 2013. Green synthesis of silver nanoparticles by Chrysanthemum morifolium extract and their application in clinical ultrasound gel. Int. J. Nanomedicine, 8: 1809-1815.

Ismail Ocsoy, Mathews Paret, Muserref Arslan Ocsoy, Sanju Kunwar, Tao Chen, Mingxu You and Weihong Tan. 2013. Nanotechnology in plant disease management: DNA-directed silver nanoparticles on graphene oxide as an antibacterial against Xanthomonas perforans. ACS Nano., 7(10): 8972-8980.

Jo, Y.K and B.H. Kim. 2009. Antifungal activity of silver ions and nanoparticles on phytopathogenic fungi. Plant Disease, 93 (10): 1037 - 1043.

Joseph, T and M. Morrison. 2006. Nanotechnology in agriculture and food. Nanoforum Report, Institute of Nanotechnology. Pp: 1-13.

Jung, J.H. S.W. Kim, J.S. Min, Y.J Kim, K. Lamsal, K.S Kim and Y.S Lee. 2010. The effect of nanosilver liquid against the white rot of the green onion caused by Sclerotium cepivorum. Mycobiology, 38(1): 39-45.

Kim, S.W., J.H Jung, K. Lamsal, Y.S. Kim, J.S
Min and Y.S Lee. 2012. Antifungal effects of silver nanoparticles (AgNPs) against various plant pathogenic fungi. Mycobiology, 40(1): 53-58.

Krishnaraj, C., R. Ramachandran, K. Mohan and P.T. Kalaichelvan. 2012. Optimization for rapid synthesis of silver nanoparticles and its effect on phytopathogenic fungi. Spectrochimica Acta Part A: Molecular and Biomolecular Spectroscopy, 93: 95- 99.

Kucharska, K., E. Pezowicz, D. Tumialis, D. Kucharski, B. Zajdel. 2009. The effect of silver nanoparticles on mortality and pathogenicity of entomopathogenic nematodes Heterorhabditis bacteriophora (Poinar, 1976) from Nematop biopreparation. Animal Science, 48: 21-23.

Kucharska, K., E. Pezowicz, D. Tumialis, D. Kucharski, B. Zajdel. 2014. Nanoparticles of silver and copper on entomopathogenic nematodes Steinernema feltiae (Filipjev, 1934) in reducing the number of the lesser mealworm beetle Alphitobius diaperinus (Panzer, 1797). Animal Science, 53: 29-35.

Lamsal, K., S.W. Kim, J.H. Jung, Y.S. Kim, K.S Kim and Y.S. Lee. 2011. Application of silver nanoparticles for the control of Colletotrichum species in vitro and pepper anthracnose disease in field. Mycobiology, 39(3): 194-199.

Lim, D.Y., Y. Ji-Yeon Roh, Y. Hyun-Jeong Eom, Z. Jeong-Yun Choi, S. Jinwon Hyun and Jinhee Choi. 2012. Oxidative stress-related PMK-1 p38 MAPK activation as a mechanism for toxicity of silver nanoparticles to reproduction in the nematode Caenorhabditis elegans. Environmental Toxicology and Chemistry, 31(3): 585-592.

Mahmood Chahardooli, Ehsan Khodadadi and Ehsaneh Khodadadi. 2014. Green synthesis of silver nanoparticles using oak (Quercus infectoria) leaf and fruit extracts and its antibacterial activity against plant pathogenic bacteria. International Journal of Biosciences, 4(3): 97-103.

Meyer, J.N., C.A. Lord, X.Y. Yang, E. Turner, A.R. Badireddy, S.M. Marinakos, A. Chilkoti, M.R. Wiesner and M. Auffan. 2010. Intracellular uptake and associated toxicity of silver nanoparticles in 
Caenorhabditis elegans. Aquatic Toxicology, 100: 140-150.

Min, J.S., K.S. Kim, S.W. Kim, J.H. Jung, K. Lamsal, S.B. Kim, M. Jung and Y.S. Lee. 2009. Effects of colloidal silver nanoparticles on sclerotium forming phytopathogenic fungi. Plant Pathol. J., 25(4): 376-380.

Nair, R., S.H. Varghese, B.G. Nair, T. Maekawa, Y. Yoshida and D.S. Kumar. 2010. Nanoparticulate material delivery to plants. Plant Science, 179(3): 154-163.

Narayanan, K.B and H.H. Park. 2014. Antifungal activity of silver nanoparticles synthesized using turnip leaf extract (Brassica rapa L.) against wood rotting pathogens. Eur. J. Plant. Pathol., 65: 1-8.

Ouda, S.M. 2014. Antifungal activity of silver and copper nanoparticles on two plant pathogens, Alternaria alternata and Botrytis cinerea. Research Journal of Microbiology, 9 (1): 34-42.

Papaiah, S., T.E. Seshadri Goud, B.S. Devi Prasad, K. Vemana and G. Narasimha. 2014. Silver nanoparticles a potential alternative to conventional antifungal agents to fungal pathogens affecting crop plants. International Journal of Nano Dimension, 5(2): 139-144.

Park, H.J., S.H. Kim, H.J. Kim and S.H. Choi. 2006. A new composition of nanosized silica-silver for control of various plant diseases. Plant Pathol. J., 22: 295-302

Pulit, J., M. Banach, R. Szczygłowska and M. Bryk. 2013. Nanosilver against fungi. Silver nanoparticles as an effective biocidal factor. Acta Biochimica Polonica, 60(4): 795-798.

Rajesh, S., D.P. Raja, J.M. Rathi and K. Sahayaraj. 2012. Biosynthesis of silver nanoparticles using Ulva fasciata (Delile) ethyl acetate extract and its activity against Xanthomonas campestris pv. malvacearum. J. Biopest., 5: 119-128.

Sahayaraja, K., S. Rajesh and J.M. Rathib. 2012. Silver nanoparticles biosynthesis using marine alga Padina Pavonica (Linn.) and its microbicidal activity. Digest Journal of Nanomaterials and Biostructures, 7(4): 1557-1567

Sandhya, M., B.R. Singh, A. Singh, C. Keswani, A.H. Naqvi and H.B. Singh. 2014. Biofabricated silver nanoparticles act as a strong fungicide against Bipolaris sorokiniana causing spot blotch disease in wheat. Plos One, 9(5): 1-11.

Wani, A.H and M.A. Shah. 2012. A unique and profound effect of $\mathrm{MgO}$ and $\mathrm{ZnO}$ nanoparticles on some plant pathogenic fungi. Journal of Applied Pharmaceutical Science, 2: 40-44.

Yang, X., A.P. Gondikas, J.N. Meyer, S. M. Marinakos, M. Auffan, J. Liu and H.H. Kim. 2012. Mechanism of silver nanoparticle toxicity is dependent on dissolved silver and surface coating in Caenorhabditis elegans. Environmental Science and Technology, 46: 1119-1127.

Yehia, R.S and Osama F. Ahmed. 2013. In vitro study of the antifungal efficacy of zinc oxide nanoparticles against Fusarium oxysporum and Penicilium expansum. African Journal of Microbiology Research, 7(19): 1917-1923.

Yeon Roh, J., S.J. Sim, J. Yi, K. Park, K.H Chung, D.Y. Ryu and J.H Choi. 2009. Ecotoxicity of silver nanoparticles on the soil nematode Caenorhabditis elegans using functional ecotoxicogenomics. Environ. Sci. Technol., 43: 3933-3940.

\section{How to cite this article:}

Surega. R, B. Anita and Ramakrishnan. S. 2020. Management of Plant Pathogens using Silver Nanoparticles (AgNPs). Int.J.Curr.Microbiol.App.Sci. 9(02): 1932-1938. doi: https://doi.org/10.20546/ijcmas.2020.902.220 